\title{
Rancang Bangun Alat Pendeteksi Pencurian Barang Pada Truk Muatan Menggunakan Sensor PIR berbasis SMS Gateway
}

\author{
Reyhan Prayogi ${ }^{1}$, Oriza Candra ${ }^{2}$ \\ ${ }^{12}$ Universitas Negeri Padang \\ Jl. Prof Dr. Hamka Air Tawar, Padang Indonesia \\ reyhanprayogi990@gmail.com,orizacandra@ft.unp.ac.id
}

\begin{abstract}
Our country Indonesia is a country consisting of various islands. Most industries in Indonesia use land transportation services as a means of distributing raw materials and processed materials to various regions. It is not uncommon for trucks carrying processed goods to be burglarized by criminals. Therefore, it is necessary to design a system that can detect this crime. In this case, the system design will use the method of tracking location coordinates by the GPS module as a coordinate reading device. A PIR sensor will be installed on the container box to detect the movement of the thief, the buzzer as a shock alarm will sound, after that the GPS module reads the coordinates of the location, at the same time the Bluetooth module as an additional device will provide a signal to the driver via the bluetooth application as a notification that the payload has been breached. The SIM module as a connecting device to the web server will send SMS coordinates of the location of the incident to the local security party. The location can also be updated via a specially designed android application. From the testing and analysis that has been done, the results of the presentation of the success of the system performance are $100 \%$. Testing the location coordinates on the GPS system with GPS on a smartphone has an average distance difference of 9.65 meters with an accuracy presentation of $99 \%$ for GPS systems and $96.5 \%$ for GPS on smartphones. Meanwhile, the average time required for the SIM module to send SMS is 20 seconds with a $100 \%$ success presentation of SMS.
\end{abstract}

Keywords - Modul GPS, Modul SIM, Modul Bluetooth, Buzzer, Sensor PIR

\begin{abstract}
Abstrak - Negara kita indonesia merupakan negara yang terdiri dari berbagai pulau-pulau. Sebagian besar perindustrian yang ada di indonesia menggunakan jasa transportasi darat sebagai sarana pendistribusian bahan baku dan bahan hasil olahan keberbagai wilayah yang ada. Tidak jarang truk muatan pengangkut barang olahan sering dibobol oleh pelaku-pelaku kriminal. Oleh karenanya perlu dirancang sebuah sistem yang dapat mendeteksi tindak kriminalitas ini. Dalam hal ini rancangan sistem akan menggunakan metode pelacakan koordinat lokasi oleh modul GPS selaku piranti pembacaan koordinat. Sebuah sensor PIR akan dipasang pada box konteiner untuk melakukan pendeteksian terhadap pergerakan pencuri, buzzer selaku alarm kejut akan berbunyi, setelah itu modul GPS melakukan pembacaan Koordinat lokasi, dalam waktu yang bersamaan modul Bluetooth selaku piranti tambahan akan memberikan sinyal kepada pengemudi melalui aplikasi bluetooth sebagai notifikasi bahwa muatan sudah dibobol. Modul SIM selaku piranti penghubung ke web server akan mengirimkan SMS koordinat lokasi kejadian kepihak keamanan setempat. Lokasi juga dapat diUpdate melalui aplikasi android yang sudah dirancang khusus. Dari pengujian dan analisa yang sudah dilakukan maka didapat hasil presentasi keberhasilan kinerja sistem sebesar $\mathbf{1 0 0 \%}$. Pengujian koordinat lokasi pada GPS sistem dengan GPS pada smartphone memiliki selisih jarak rata-rata sebesar 9,65 meter dengan presentasi keakuratan 99\% untuk GPS sistem dan 96,5\% untuk GPS pada smartphone. Sedangakan waktu rata-rata yang dibutuhkan modul SIM untuk mengirimkan SMS adalah selama 20 detik dengan presentasi keberhasilan pengiriman SMS sebesar $100 \%$.
\end{abstract}

Kata kunci-Modul GPS, Modul SIM, Modul Bluetooth, Buzzer, Sensor PIR

\section{Pendahuluan}

Pada era modern sekarang ini seluruh kegiatan yang ada di industri, baik industri besar ataupun industri menengah kebawah. Semua nya menggunakan jasa transportasi baik darat, laut, maupun udara untuk keperluan pendistribusian barang-barang hasil produksinya. "Transportasi merupakan sarana yang sangat penting dalam menunjang keberhasilan pembangunan terutama dalam mendukung kegiatan perekonomian masyarakat tak terkecuali di daerah perdesaan. Transportasi merupakan aspek penting dalam menentukan keberhasilan sebuah industri. Karena denganya produk- 
produk hasil produksi sebuah industri dapat tersalurkan dengan baik kekonsumen. Salah satu transportasi yang sering digunakan oleh perindustrian yang ada di indonesia adalah transportasi darat, salah satunya adalah Truk konteiner.

Sebagai jasa transportasi yang cukup penting dalam pendistribusian barang dan jasa, tak sedikit pula rintangan dan bahaya yang dialami oleh pengemudi truk konteiner, mulai dari kendala teknis, kecelakaan lalu lintas dan lain sebagainya. Salah satu rintangan dan kerugian yang dihadapi oleh pengemudi truk ialah adanya orangorang tidak bertanggung jawab yang mencuri barang atau beban yang di angkut truk konteiner atau yang sering disebut dengan bajing loncat. Oleh karenanya perlu adanya sebuah sistem yang dirancang untuk mendeteksi adanya pencurian barang, sehingga denganya pengemudi sopir truk dapat mengantisipasi tindakan kriminalitas tersebut. Disini penulis ingin merancang sebuah sistem yang dapat mendeteksi adanya terjadi pencurian barang dalam box konteiner, dimana sebuah piranti sensor dipasang kedalam box konteiner, lalu apabila sensor tersebut mendeteksi adanya sebuah gerakan yang tak wajar maka GPS akan menentukan koordinat lokasi truk berada dan modul GSM selaku piranti penghubung ke webserver akan mengirimkan pesan berupa informasi terkini terkait lokasi kejadian kriminal tersebut kepada pos pihak keamanan terdekat. Dalam waktu yang bersamaan modul Bluetooth akan mengirimkan sinyal berupa notifikasi aplikasi kepada pengemudi melalui perangkat android. Manfaat dari pembuatan tugas akhir ini diharapkan dapat meningkatkan efisiensi ekspor impor suatu industri dalam mendistribusikan produk hasil olahan melalui jasa truk konteiner dengan meningkatkan sistem keamanan pada truk konteiner sehingga tingkat kriminalitas dapat berkurang.

\section{Metode}

Metode penelitian pada rancangan sistem pendeteksi pencurian barang pada truk adalah meliputi simulasi alat baik secara hardware ataupun software.

\section{PERANCANGAN DAN PEMBUATAN ALAT \\ A. Blok Diagram}

Blok diagram adalah dalah satu metode yang dapat digunakan dalam menggambarkan secara umum bagaimana cara kerja alat secara menyeluruh. Perancangan secara umum dari "Rancang Bangun Alat Pendeteksi Pencurian Barang Pada Truk Konteiner Menggunakan sensor PIR berbasis SMS dapat dilihat pada gambar 1 berikut ini

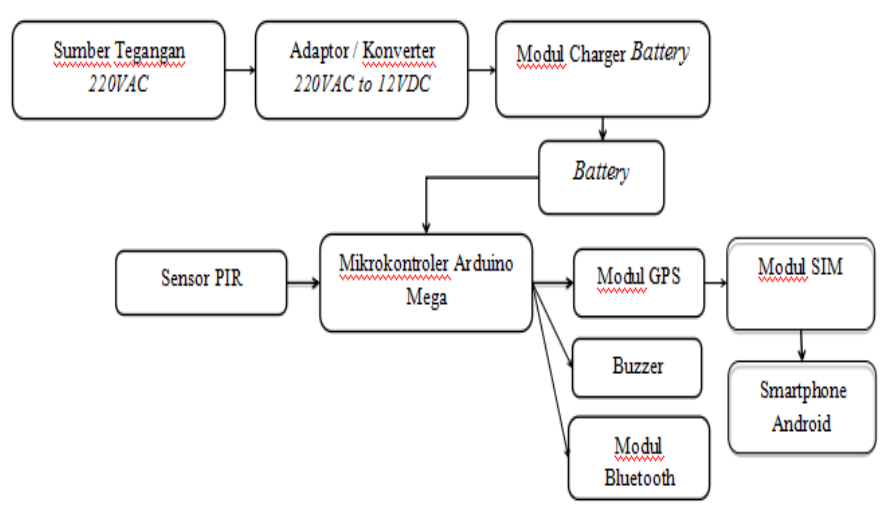

Gambar 1. Blok Diagram Alat

Berikut penjelasan dari gambar blok diagram diatas:

1. Sumber tegangan.

Berfungsi sebagai penyuplai tegangan atau sumber tegangan untuk komponen-komponen yang ada pada rangkaian alat. Tegangan awal pada rangkaian adalah 220 VAC (sumber PLN). Setelah itu adaptor akan mengubah bentuk tegangan menjadi DC (arus searah). tegangan DC inilah yang nantinya akan menjadi suplai utama bagi mikrokontroler dan komponen lainya.

2. Adaptor/konverter.

Seperti yang telah dijelaskan pada point sebelumnya, adaptor berfungsi mengubah bentuk tegangan AC yang bersumber dari PLN menjadi bentuk tegangan DC dengan nilai tegangan $12 \mathrm{~V}$.

3. Modul charger battery.

Berfungsi sebagai modul untuk menyuplai tegangan dari adaptor menuju baterai. Modul ini memiliki tegangan input $12 \mathrm{vdc}$ dan tegangan keluaran $5 \mathrm{vdc}$, modul ini hanya digunakan ketika baterai dalam keadaan habis, jadi modul ini memiliki arti lain sebagai charger untuk baterai.

4. Battery

Berfungsi sebagai suplai tegangan untuk mikrokontroler dan komponen lainya.

5. Mikrokontroler arduino mega

Berfungsi sebagai pusat pengolahan data / pusat kendali, semua instruksi yang telah diprogram dijalankan oleh mikrokontroler sebagai otak dari rangkaian alat.

6. Sensor PIR (Passive Infrared Receiver)

Berfungsi sebagai perangkat yang mendeteksi adanya pergerakan disekitar area cakupan sensor.

7. Modul GPS

Berfungsi sebagai piranti yang menentukan koordinat lokasi kejadian perkara secara realtime.

8. Buzzer / Alarm

Berfungsi sebagai piranti yang memberikan notifikasi berupa suara kepada pengemudi sekaligus sebagai alat kejut bagi pencuri.

9. Modul Bluetooth

Berfungsi sebagai notifikasi tambahan bagi sipengemudi jika modul $\aleph_{\mathrm{m}}$ tidak dapat mengirimkan sinyal karna masalah sinyal. 


\section{Modul SIM}

Berfungsi sebagai piranti yang menghubungkan alat ke jaringan web server. Alat ini akan mengirimkan informasi berupa SMS kepada server pos keamanan terdekat.

\section{B. Cara Kerja Alat}

Dengan flowchart yang ada maka dapat diketahui dengan jelas mekanisme alat mulai dari input proses dan outputnya. Berikut penjelasan algoritmanya :

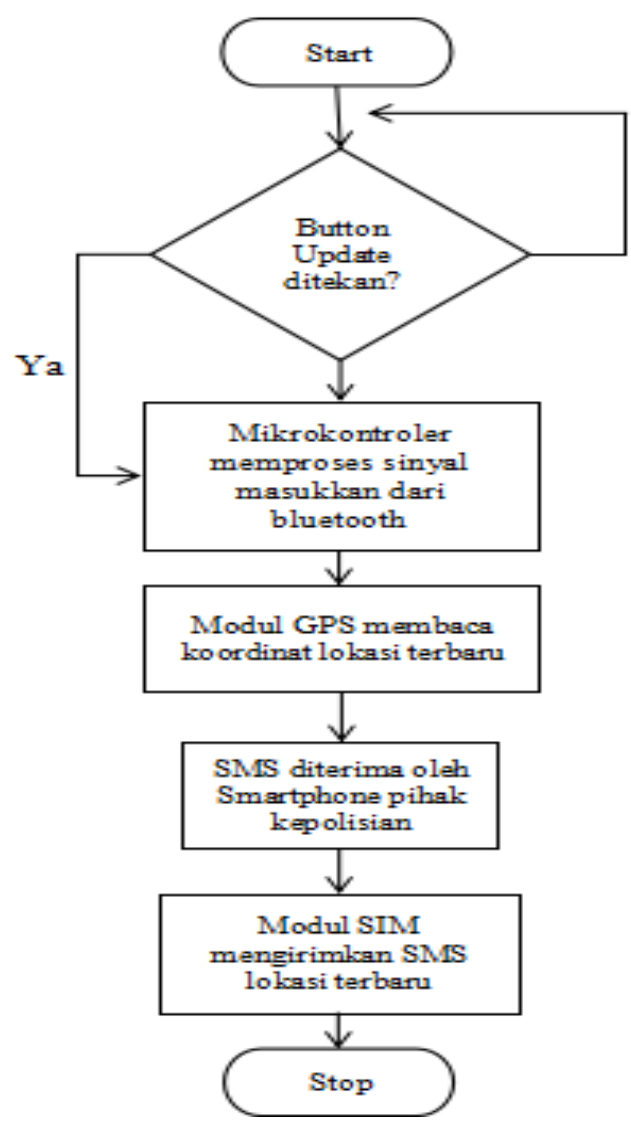

Gambar 2. Flowchart sistem saat lokasi di Update

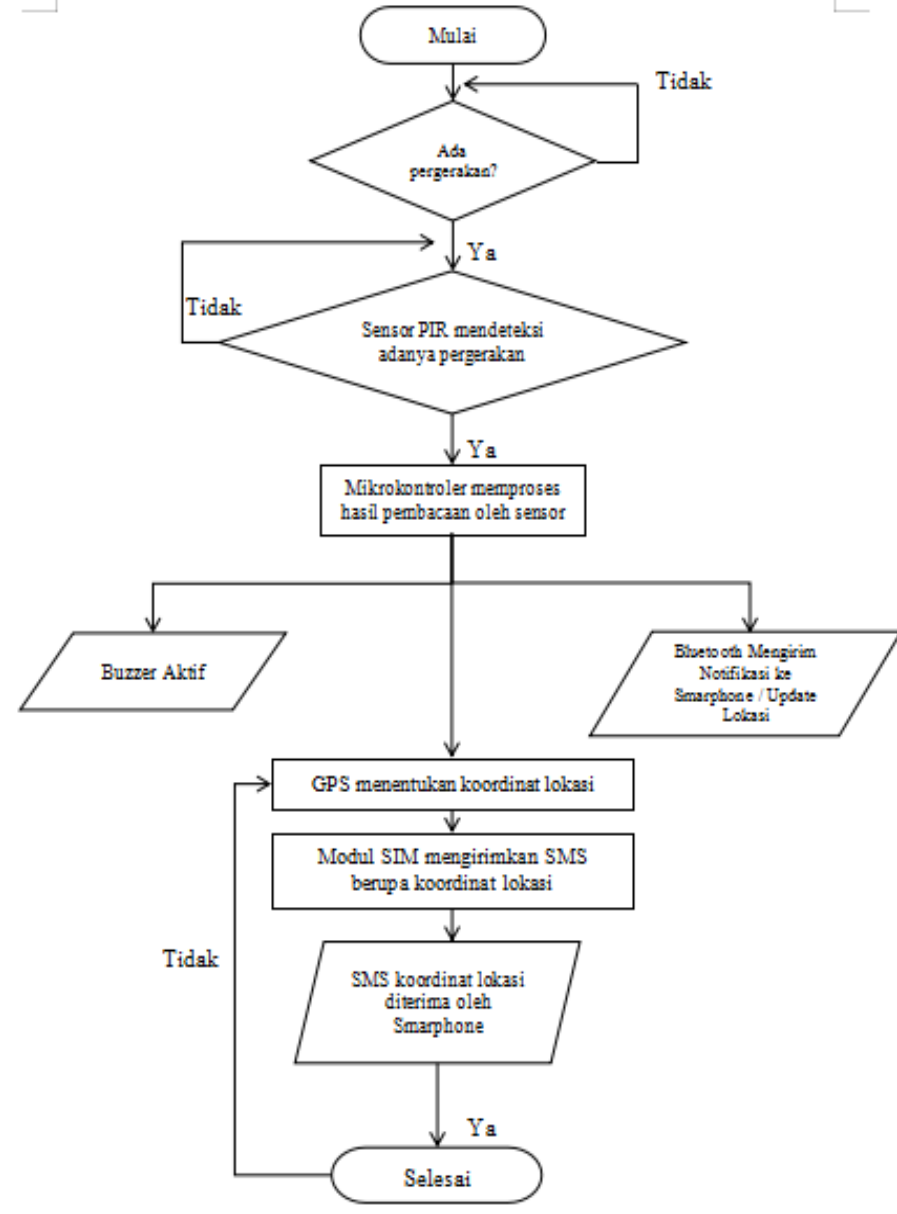

Gambar 3. Flowchart sistem saat mendeteksi adanya
pembobolan Muatan

Berikut penjelasan algoritmanya :

1. Mulai

2. Sensor PIR mendeteksi adanya pergerakan

3. Mikrokontroler memproses pembacaan sensor

4. Modul GPS dan Buzzer aktif

5. Modul Bluetooth mengirimkan notifikasi kepada aplikasi android

6. Proses menentukan koordinat lokasi

7. Modul SIM mengirimkan SMS berupa koordinat lokasi

8. Smartphone menerima SMS berupa koordinat lokasi kejadian.

9. Update lokasi jika truk berpindah.

10. Selesai

\section{Perancangan Hardware}

Perancangan hardware alat ini dibuat menyerupai truk konteiner atau bisa dibilang prototype truk konteiner tujuanya ialah agar alat dapat bekerja sesuai dengan keadaan yang sesungguhnya. Hal ini akan menambah efisiensi alat apabila diterapkan pada kondisi atau keadaan yang sesungguhnya. Alat didesain seperti box, dengan panjang box $32 \mathrm{~cm}$, tinggi $12 \mathrm{~cm}$, dan lebar $21 \mathrm{~cm}$, box ini digunakan untuk meletakkan komponen-komponen alat 
seperti Arduino Modul SIM, GPS, Bluetooth dan komponen lainya. Lalu penulis juga membuat tiang penyangga berupa palang pintu untuk meletakkan sensor PIR dan Buzzer dengan tujuan agar sensor dapat mendeteksi pergerakan dan buzzer dapat didengar dengan jelas. Bahan yang digunakan sebagai material body adalah akrilik, agar alat dapat dedesain dengan mudah, serta alat menjadi lebih menarik untuk dilihat. Berikut gambar dari rancangan hardware alat ini:

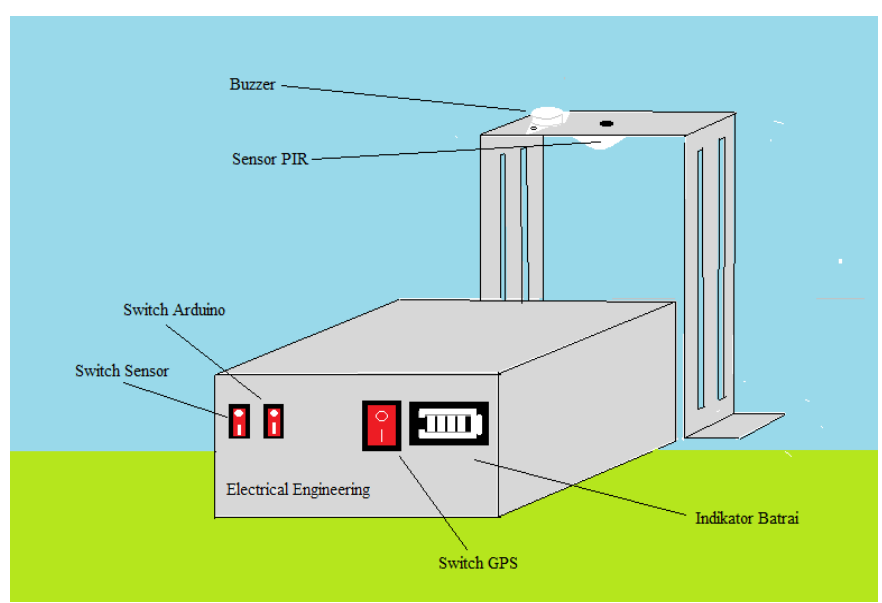

Gambar 4. Rancangan Desain Alat secara keseluruhan

\section{Perancangan Rangkaian Elektronika Secara Keseluruhan}

Rancangan alat ini menggunakan metode SMS sebagai mekanismenya, dimana ada enam buah komponen utama sebagai pondasi alat ini yang terdiri dari Board Arduino Mega dengan chip mikrokontroler Atmega2560, sensor PIR, baterai 3,7 volt sebagai sumber tegangan, modul GSM, Modul Bluetooth, dan modul SIM sebagai antarmuka yang menghubungkan alat kepada web server. Berikut rancangan elektrik alat secara keseluruhan

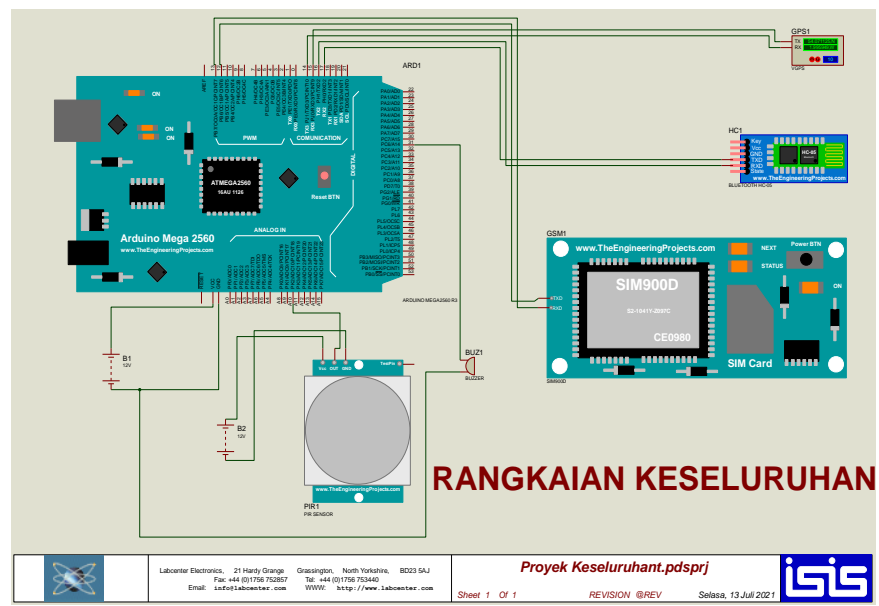

Gambar 5. Rancangan Elektronika Sistem

\section{HASIL DAN PEMBAHASAN}

Pada tahap ini akan dijelaskan bagaimana pengujian dan analisa sistem untuk membuktikan apakah sistem dapat bekerja dengan baik dan benar. Pengujian ini juga bertujuan untuk mengukur kemampuan sensor dalam mendeteksi adanya pergerakan, bagaimana modul GPS membaca koordinat lokasi dengan tepat, dan juga bertujuan untuk mengetahui kemampuan modul SIM dalam mengirimkan SMS ke smartphone.

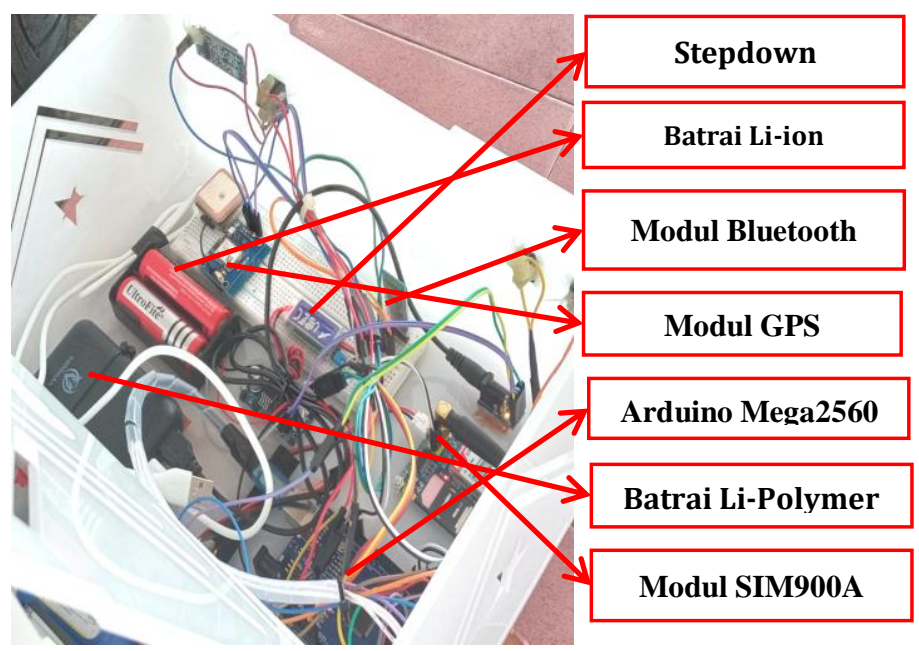

Gambar 6. Rancangan Alat Tampak Dalam BOX

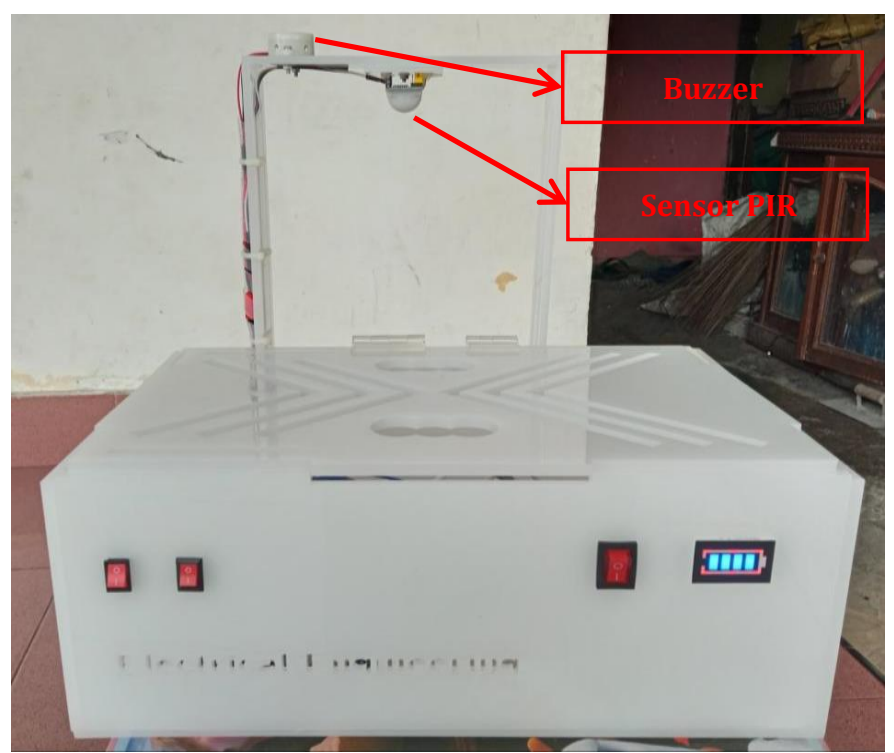

Gambar 7. Rancangan Alat Tampak Luar BOX

\section{Pengujian Modul GPS}

Pada bagian ini akan dijelaskan bagaimana keakuratan pembacaan koordinat lokasi oleh modul GPS. Program akan didesain dengan menentukan pembacaan modul GPS dengan jeda lima detik. Penulis akan berada dilokasi yang sama dengan tujuan mengamati hasil pembacaan program setiap lima detik. 
Tabel 1. Pengujian perbandingan GPS Sistem dengan GPS pada Smartphone

\begin{tabular}{|c|c|c|c|c|}
\hline \multicolumn{2}{|c|}{$\begin{array}{l}\text { Hasil Pembacaan } \\
\text { Koordinat oleh } \\
\text { Sistem (Alat) }\end{array}$} & \multicolumn{2}{|c|}{$\begin{array}{c}\text { Hasil Pembacaan } \\
\text { Koordinat oleh } \\
\text { Smartphone } \\
\text { Android }\end{array}$} & \multirow{2}{*}{$\begin{array}{c}\text { Selisih } \\
\text { jarak } \\
\text { Koordin } \\
\text { at } \\
\text { (Meter) }\end{array}$} \\
\hline Latitude & $\begin{array}{c}\text { Longitud } \\
\text { e }\end{array}$ & Latitude & $\begin{array}{c}\text { Longitud } \\
\mathrm{e}\end{array}$ & \\
\hline-0.901917 & $\begin{array}{c}100.36177 \\
8\end{array}$ & -0.901944 & $\begin{array}{c}100.36169 \\
3\end{array}$ & $\begin{array}{c}9,46 \\
\text { meter }\end{array}$ \\
\hline
\end{tabular}

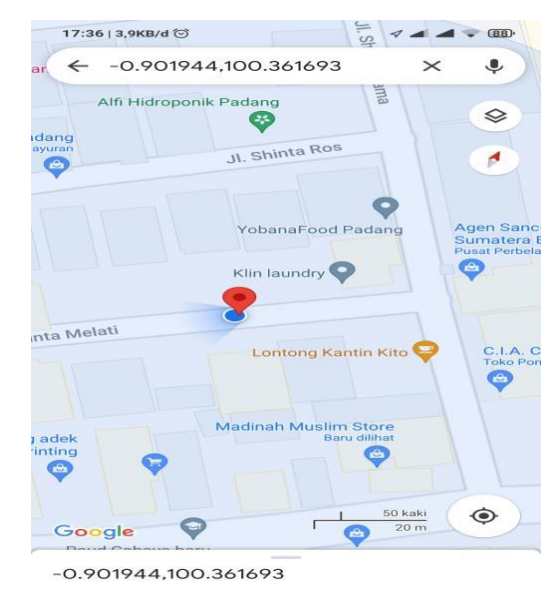

Gambar 8. Pembacaan lokasi oleh Smartphone Android

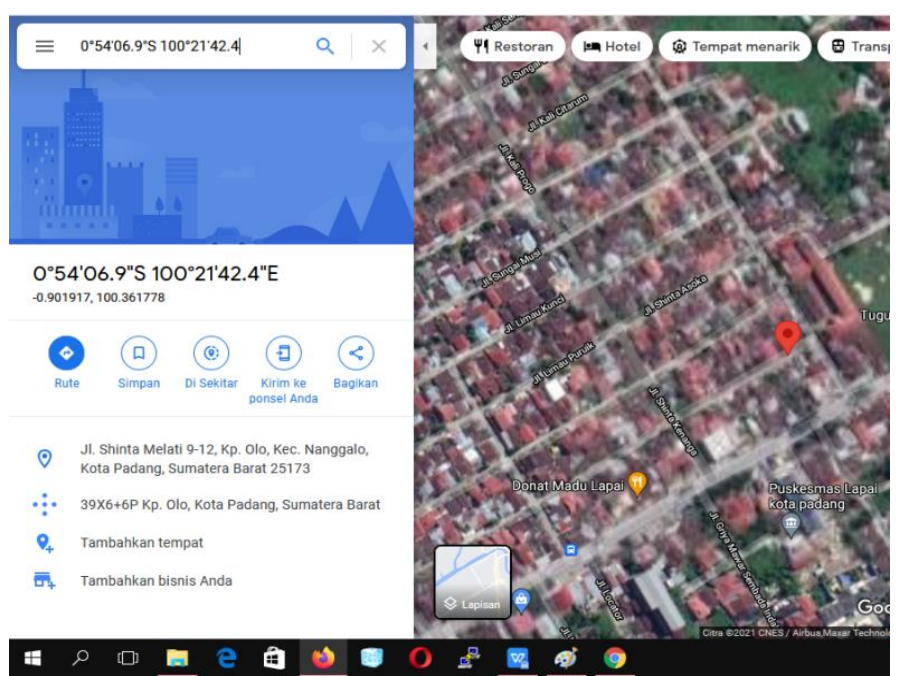

Gambar 9. pembacaan lokasi oleh Modul GPS rancangan alat

Selisih jarak koordinat $=\sqrt{\text { jarak latitude }{ }^{2}+\text { jarak longitude }}{ }^{2}$ Selisih jarak koordinat $=\sqrt{2,956^{2}+9,307^{2}}$

Selisih jarak koordinat $=$ 9,46 meter

Dalam pengujian diatas didapat presentasi keakuratan GPS sistem sebesar 99\% sementara GPS pada smartphone sebesar 96,5\%. Pengujian diatas bertujuan untuk menunjukkan efisiensi sistem dalam menentukan koordinat lokasi, terbukti GPS sistem memliki presentasi yang lebih besar dari smartphone GPS.

\section{Pengujian Modul SIM}

Pengujian ini dilakukan untuk mengetahui kemampuan Modul SIM mengirimkan SMS ke smartphone pihak yang berwajib. Parameter yang dijadikan sebagai pergitungan adalah lokasi pengujian, yang mana meiliki empat kategori, yaitu lokasi Pusat Kota, Pinggir Kota Perbatasan Kota, dan Perbatasan Kabupaten kota. Serta parameter waktu juga dijadikan tolak ukur dalam pengujian ini. Berikut tabel pengamatanya :

\section{Tabel 2. Pengujian Modul SIM900A}

\begin{tabular}{|c|c|c|c|c|}
\hline No & Lokasi Kejadian & $\begin{array}{l}\text { Waktu } \\
\text { Pesan } \\
\text { Masuk }\end{array}$ & $\begin{array}{l}\text { Status } \\
\text { Pesan }\end{array}$ & $\begin{array}{c}\text { Delay } \\
\text { Waktu } \\
\text { Pesan } \\
\text { Masuk } \\
\text { (Detik) }\end{array}$ \\
\hline 1 & $\begin{array}{l}\text { Pusat Kota (Lapai, } \\
\text { Kota Padang) }\end{array}$ & $\begin{array}{l}10: 56 \\
\text { WIB }\end{array}$ & Diterima & 20 detik \\
\hline 2 & $\begin{array}{c}\text { Pinggir Kota } \\
\text { (Jl.Bypasskm.7) }\end{array}$ & $\begin{array}{l}10: 01 \\
\text { WIB }\end{array}$ & Diterima & 20 detik \\
\hline 3 & $\begin{array}{c}\text { Perbatasan } \\
\text { Kota(Bungus) }\end{array}$ & $\begin{array}{l}10.22 \\
\text { WIB }\end{array}$ & Diterima & 22 detik \\
\hline 4 & $\begin{array}{c}\text { Perbatas } \\
\text { Kabupaten Kota } \\
\text { (Perbatasan } \\
\text { Pessel-padang) }\end{array}$ & $\begin{array}{l}11.07 \\
\text { WIB }\end{array}$ & Diterima & 19 detik \\
\hline & Waktu Rata-rata & esan Ma & & $\begin{array}{l}20,25 \\
\text { detik }\end{array}$ \\
\hline
\end{tabular}

Dari hasil pengamatan data yang ada pada table diatas dapat dijelaskan dari empat kali percobaan dapat dilihat waktu pesan masuk tercepat yaitu 19 detik dan waktu terlama yaitu 22 detik. Perbedaan dari waktu pengiriman pesan tersebut dapat dipengaruhi oleh kondisi sinyal pada saat pengujian. Waktu rata-rata saat pengujian yaitu :

Waktu Rata-Rata $=\frac{\sum \text { Waktu Pesan Masuk }}{\text { Jumlah Pengujian }}$

Waktu Rata-Rata $=\frac{81}{4}$

Waktu Rata-Rata $=\mathbf{2 0 , 2 5}$ detik

Dengan presentasi keberhasilan pesan diterima $=\mathbf{1 0 0} \%$

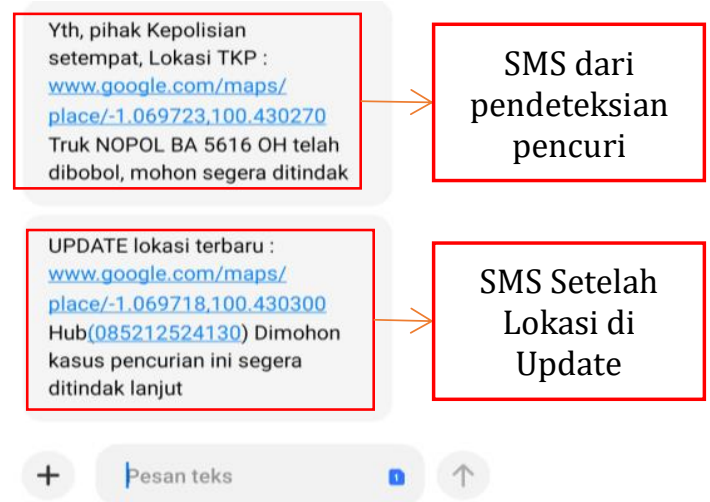

Gambar 10. Pesan Teks yang masuk ke Smartphone 
Pada gambar 10 terdapat dua pesan teks yang berbeda, pesan teks pertama merupakan SMS pemberitahuan awal bahwa truk telah dibobol oleh pencuri. Sedangkan pesan teks kedua merupakan SMS pemberitahuan jika posisi truk berpindah dari lokasi yang pertama.

\section{Pengujian Modul Bluetooth}

Pengujian ini bertujuan untuk menjelaskan mekanisme pengoperasian modul bluetooth agar dapat berkomunikasi dengan aplikasi android yang sudah dirancang sebagai antarmuka untuk memberitahu pengemudi truk bahwa muatan sudah dibobol. Pengujian meliputi langkah-langkah menghububungkan aplikasi dengan sistem, dan pengujian kemampuan modul bluetooth dalam menerima sinyal dari smartphone dengan jarak sebagai parameternya.

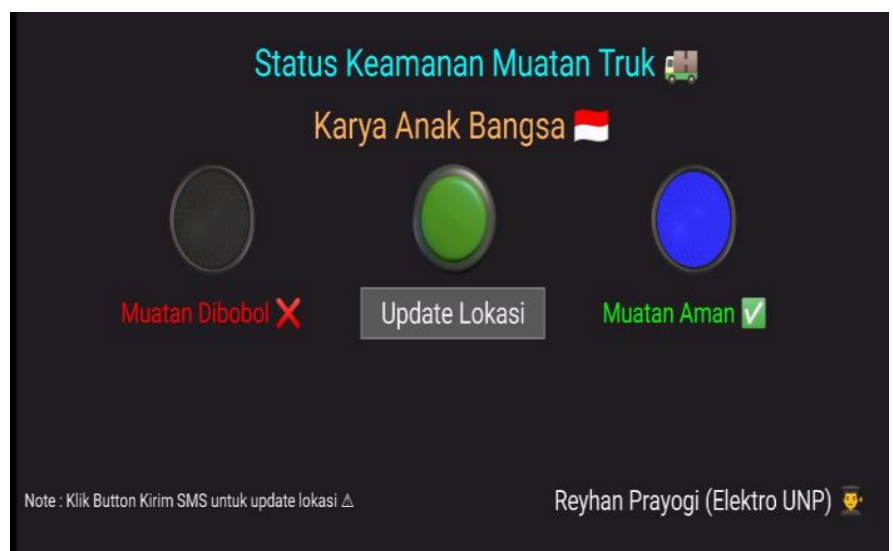

Gambar 11. Tampilan Aplikasi saat muatan truk dalam keadaan aman

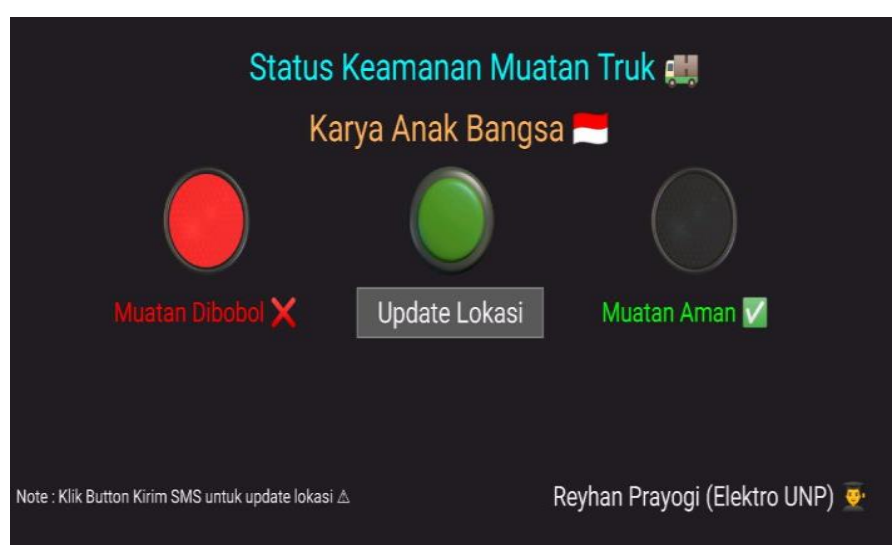

Gambar 12. Tampilan Aplikasi saat muatan truk dibobol.

Berdasarkan gambar 11 dan 12 diatas, dapat dijelaskan bahwa tampilan aplikasi memiliki tiga fungsi utama, terdapat tombol Update Lokasi yang berfungsi untuk memperbaharui lokasi jika truk berpindah posisi, pada tampilan aplikasi juga terdapat dua buah LED notifikasi yang memiliki fungsi yang berbeda. LED biru sebagai tanda bahwa kondisi truk dalam keadaan aman, sedangkan LED merah berfungsi sebagai tanda bahwa truk telah dibobol oleh pencuri. LED merah akan berkedip sebanyak 3 kali setiap 1 detik, dan setelahnya LED akan kembali bewarna biru.

Pengujian ini bertujuan untuk mengetahui kemampuan modul bluetooth untuk berkomunikasi dengan smatphone yang terhubung. Paramter yang dijadikan pengujian adalah jarak antara smartphone dengan modul bluetooth yang ada dalam box alat. Dengan adanya pengujian ini maka bisa ditetapkan jarak peletakan antara box dengan sensor yang ada dipermukaan pintu konteiner

Tabel 3. Pengujian Jarak Koneksi Modul Bluetooth

\begin{tabular}{cc}
\hline Jarak Pengujian & Status Koneksi \\
\hline 3 meter & Terhubung \\
\hline 6 meter & Terhubung \\
\hline 7 meter & Terhubung \\
\hline 9 meter & Terhubung \\
\hline
\end{tabular}

\section{Pengujian Sensor PIR}

Pada bagian ini akan dijelaskan bagaimana kemampuan sensor dalam mendeteksi adanya pergerakan. Parameter pengukuran adalah berdasarkan jarak dan intensitas cahaya. Berikut data hasil pengukuranya:

Tabel 4. Pengujian Jarak Pendeteksian oleh Sensor

\begin{tabular}{ccccc}
\hline $\begin{array}{c}\text { Pengu } \\
\text {-jian }\end{array}$ & Jarak & Siang Hari & $\begin{array}{c}\text { Malam } \\
\text { Hari }\end{array}$ & $\begin{array}{c}\text { Prese } \\
\text { n-tasi } \\
\text { Keber } \\
- \\
\text { hasila } \\
\text {-n }\end{array}$ \\
\hline 1 & 1 meter & $\begin{array}{c}\text { Terdeteks } \\
\text { i }\end{array}$ & Terdeteksi & $100 \%$ \\
\hline 2 & 2 meter & $\begin{array}{c}\text { Terdeteks } \\
\text { i }\end{array}$ & Terdeteksi & $100 \%$ \\
\hline 3 & 3 meter & $\begin{array}{c}\text { Terdeteks } \\
\text { i }\end{array}$ & Terdeteksi & $100 \%$ \\
\hline 4 & 4 meter & $\begin{array}{c}\text { Terdeteks } \\
\text { i }\end{array}$ & $\begin{array}{c}\text { Tidak } \\
\text { Terdeteksi }\end{array}$ & $50 \%$ \\
\hline
\end{tabular}

\section{Pengujian Alat Secara Keseluruhan}

Pengujian ini bertujuan untuk mengetahui kinerja alat secara keseluruhan, mulai dari sensor mendeteksi adanya pergerakan, modul GPS membaca koordinat lokasi, bluetooth mengirimkan notifikasi kepada pengemudi dan terakhir modul sim berhasil mengirimkan pesan ke smartphone.

Pada tabel 5 terdapat 4 pengujian dilokasi yang berbeda-beda. Penentuan lokasi berdasarkan area yang memiliki cangkupan sinyal terkuat sampai yang dianggap terlemah. Dalam 4 pengujian tersebut, modul GPS sudah cukup akurat dalam menentukan koordinat lokasi, modul SIM juga memiliki kestabilan dalam hal pengiriman pesan 
dengan rata-rata 20 detik disetiap lokasi. Modul bluetooth juga dapat berkomunikasi dengan aplikasi pada smartphone untuk menampilkan notifikasi tambahan pada sipengemudi truk.

Tabel 5. Pengujian Alat Secara Keseluruhan

\begin{tabular}{|c|c|c|c|c|c|c|}
\hline \multirow{2}{*}{$\begin{array}{l}\mathbf{N} \\
\mathbf{0} \\
\end{array}$} & \multirow{2}{*}{$\begin{array}{c}\text { Lokasi } \\
\text { Pengujia } \\
\text { n }\end{array}$} & \multicolumn{2}{|c|}{ Koordinat } & \multirow{2}{*}{$\begin{array}{c}\text { Stat } \\
\text { us } \\
\text { SMS } \\
\end{array}$} & \multirow{2}{*}{$\begin{array}{c}\text { Status } \\
\text { Bluet } \\
\text { ooth } \\
\end{array}$} & \multirow{2}{*}{$\begin{array}{c}\text { Status } \\
\text { Penguj } \\
\text { i-an } \\
\end{array}$} \\
\hline & & $\begin{array}{c}\text { Latitud } \\
\text { e } \\
\end{array}$ & longtude & & & \\
\hline 1 & $\begin{array}{c}\text { Bypass } \\
\text { km 7, } \\
\text { Kota } \\
\text { Padang } \\
\end{array}$ & $\begin{array}{c}- \\
0.9378 \\
76\end{array}$ & $\begin{array}{c}100.3995 \\
10\end{array}$ & $\sqrt{ }$ & $\sqrt{ }$ & $\begin{array}{c}\text { Berhasi } \\
l\end{array}$ \\
\hline 2 & $\begin{array}{l}\text { Bungus, } \\
\text { Teluk } \\
\text { Kabung } \\
\end{array}$ & $\begin{array}{c}- \\
1.0061 \\
45\end{array}$ & $\begin{array}{c}100.3859 \\
60 \\
\end{array}$ & $\sqrt{ }$ & $\sqrt{ }$ & $\begin{array}{c}\text { Berhasi } \\
\text { l }\end{array}$ \\
\hline 3 & $\begin{array}{l}\text { Perbatas } \\
\text {-an } \\
\text { Pessel - } \\
\text { Padang }\end{array}$ & $\begin{array}{c}- \\
1.0697 \\
18\end{array}$ & $\begin{array}{c}100.4303 \\
00\end{array}$ & $\sqrt{ }$ & $\sqrt{ }$ & $\begin{array}{c}\text { Berhasi } \\
l\end{array}$ \\
\hline 4 & $\begin{array}{c}\text { Lapai, } \\
\text { Kota } \\
\text { Padang }\end{array}$ & $\begin{array}{c}- \\
0.9019 \\
24\end{array}$ & $\begin{array}{c}100.3617 \\
60 \\
\end{array}$ & $\sqrt{ }$ & $\sqrt{ }$ & $\begin{array}{c}\text { Berhasi } \\
\text { l }\end{array}$ \\
\hline
\end{tabular}

Setelah dilakukan 4 pengujian dilokasi yang berbeda, didapat hasil dengan presentasi keberhasilan 100\% Presentasi Keberhasilan $=\frac{\text { jumlah pengujian berhasil }}{\text { jumlah pengujian }} \times 100 \%$ Presentasi Keberhasilan $=\frac{4}{4} \times 100 \%$ Presentasi Keberhasilan $=\mathbf{1 0 0} \%$

\section{PENUTUP}

Berdasarkan hasil pengujian dan analisa hardware, software, dan mekanik pada rancangan alat pendeteksi pencurian muatan pada truk. Maka didapat diperoleh kesimpulan sebagai berikut :

1. Perancangan sistem pendeteksi pencurian barang pada truk muatan yang memanfaatkan mikrokontroler berhasil berjalan dengan baik dan benar.

2. Pemanfaatan modul SIM900A sebagai piranti penghubung sistem dengan web server yang berfungsi sebagai media yang dapat mengirimkan SMS yang berisi informasi kriminal, dan koordinat lokasi kejadian sudah berfungsi sebagaimana mestinya. Dengan rata-rata delay waktu yang dibutuhkan untuk bisa mengirimkan SMS ke smartphone adalah 20 detik dengan tingkat keberhasilan pengiriman sebesar $100 \%$.

3. Pemanfaatan teknologi GPS sebagai fungsi untuk membaca koordinat lokasi kejadian secara realtime terbukti berhasil dalam memberikan informasi terkini lokasi pendeteksian. Pengujian yang dilakukan dengan membandingkan koordinat yang didapat GPS yang ada pada smartphone memiliki selisih sebesar 9,46 meter.
Dengan keakuratan yang didapat oleh GPS pada sistem sebesar 99\% dan GPS pada smartphone sebesar 96,5\%.

4. Rancangan sistem pendeteksi pencurian barang pada truk muatan dapat mengirimkan SMS jika modul SIM mendapat sinyal GSM. Jika sistem tidak menangkap sinyal GSM, maka alat masih dapat memberi informasi terkait pembobolan barang muatan melalui aplikasi bluetooth yang rancang untuk sipengemudi melalui notifikasi yang tampil pada aplikasi bluetooth pada smartphone.

\section{Referensi}

[1] Mukhlas, Zaki. (2018). "Alat Monitoring Beban Trafo berbasis Mikrokontroler menggunakan SMS Gateway". Tugas Akhir Teknik Elektro UNP 2018.

[2] Putra, Buana, Try, Diki. (2018). "Alat Pendeteksi Detak Jantung di Tampilkan ke smartphone Android Berbasis Mikrokontroler". Tugas Akhir Teknik Elektro UNP 2018.

[3] Amir Hamzah, Suka Aditia. (2019, Desember). "Pelacakan Lokasi Mobil Menggunakan SMS Gateway SIM800 Berbasis ATmega2560". jurnal Informatika, Manajemen dan Komputer, Vol.11 No 2.

[4] Chaniago, Alam, Palito. (2018). "Rancang Bangun Sistem Keamanan Muatan Pada Truk Barang Berbasis Mikrokontroler". Laporan Tugas Akhir Jurusan Sistem Komputer UNAND.

[5] Universitas Negeri Padang. (2015). "Buku Panduan Penulisan Tugas Akhir/Skripsi. Universitas Negeri Padang: Padang.

[6] Dewaweb. (2018). "Internet of Things". https:// www. dewaweb .com /blog/ internet-of-things/. Akses 03 Agustus 2018.

[7] Informatikalogi. (2017, 10 April). “Pengertian Flowchart dan Jenis-jenisnya". Akses from : informatikalogi.com.

[8] Larasati Hardita Novi. (2020, 23 Juni). "Pengertian GPS, Jenis dan Cara Kerjanya”. Akses from : www.diadona.id.

[9] Sukma, El hamdy Aufa, (2018). "Rancang Bangun Sistem Monitoring Karakteristik Modul Surya Menggunakan SMS Gateway". Proyek Akhir Teknik Elektro UNP 2018

[10] Sahyudimal, Mohd , (2017). "Perancangan Smarthome Berbasis Android Menggunakan Mikrokontroler Arduino UNO”. Tugas Akhir Teknik Elektro UNP 2017

[11] eprints.polsri.ac.id, (2014). "Cara Kerja Modul Bluetooth HC-05”. Laporan Akhir Politeknik Negeri Surabaya

\section{Biodata Penulis}

Reyhan Prayogi, lahir di Padang, 11 Mei 1999, menyelesaikan Program Studi DIV Teknik Elektro Industri pada jurusan Teknik Elektro Fakultas Teknik Universitas Negeri Padang.

Oriza Candra, S.T, M.T., dilahirkan di Padang,11 November 1972, menyelesaikan S1 di Universitas.A.Yani, S2 di Universitas Gadjah Mada dan S3 di Universitas Negeri Padang. Staf pengajar tetap di jurusan Teknik Elektro Fakultas Teknik Universitas Negeri Padang sampai sekarang. 